\title{
Revisiting the clinical evidence of heart rate target in patients with heart failure treated with beta-blockers
}

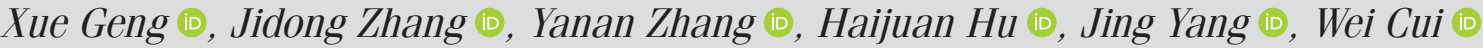 \\ Department of Cardiology, the Second Hospital of Hebei Medical University, Shijiazhuang-China
}

ABSTRACT

Objective: On evaluating the guidelines from previous studies, we found no randomized controlled trials on the use of beta-blockers for heart failure (HF) that employed as evidence for heart rate targets of 60 or 70 beats/min. In this study, we aimed to assess the target heart rate in patients with HF treated with beta-blockers.

Methods: We used the keywords, "heart failure" and "beta-blocker" to search PubMed, Ovid, EMBASE, and Cochrane from 1966 to June 2021. Two authors independently reviewed the results of the search strategy and selected all the studies that reported the effect of beta-blockers on all-cause mortality in patients with HFrEF. We conducted analyses using Review Manager, version 5.0 and Stata version 12.0. Risk of bias was assessed regarding randomization, allocation sequence concealment, blinding, incomplete outcome data, and other biases. Sensitivity analysis was carried out to compare the results of fixed effect model with the results of random effect.

Results: No clinical trial supported the optimal heart rate of 60 beats/min. Risk ratio (RR) and $95 \%$ confidence interval $(\mathrm{Cl})$ were $0.77(0.71,0.83)$ and $0.86(0.76,0.97)$ in the subgroup with a baseline heart rate $>80$ beats/min and subgroup with baseline of $\leq 80$ beats/min, respectively. RR and $95 \% \mathrm{Cl}$ were $0.92(0.82,1.02)$ and $0.77(0.65,0.92)$ in 2 subgroups with heart rate controlled $\geq 70$ beats/min and $60-70$ beats/min, respectively. Accumulated to MOCHA 1 trial (heart rate controlled 70 beats $/ \mathrm{min}$ ), there was no significant difference in mortality between the experimental group and the control group (RR=0.91, 95\% $\mathrm{Cl}$ 0.82-1.02). Accumulated to SENIORS trial (heart rate controlled 68.8 beats/min), there was a difference in mortality between the experimental and the control groups (RR=0.90, 95\% Cl 0.82-0.99).

Conclusion: The main effect of beta-blockers in the treatment of HF is achieved by lowering heart rate. The use of beta-blockers did not benefit in people with HFrEF whose heart rate was 77 beats/min before they started the treatment regimen. In patients with HFrEF, the purpose of beta-blockers is to control the heart rate to $65-70$ beats min.

Keywords: beta-blocker, heart rate, heart failure, death, ejection fraction, meta-analysis

Cite this article as: Geng X, Zhang J, Zhang Y, Hu H, Yang J, Cui W. Revisiting the clinical evidence of heart rate target in patients with heart failure treated with beta-blockers. Anatol J Cardiol 2021; 25: 762-73.

\section{Introduction}

Beta-blockers are the cornerstone of treatment for heart failure with reduced ejection fraction (HFrEF) (1,2). Current guidelines (3-5) recommend that patients with stable, symptomatic HF [New York Heart Association (NYHA) class II-IV] should start using beta blockade as early as possible and eventually continue to use it at the maximum tolerable dose. However, there are no specific targets for the use of beta blockers.

Heart rate is an independent risk factor for HF (6). An observational study involving 112,680 people showed that people in the general population with heart rate controlled at approximately 65 


\section{HIGHLIGHTS}

- This meta-analysis assesses target heart rate (HR) in patients with heart failure (HF) with reduced ejection fraction (HFrEF) treated with beta-blockers.

- This meta-analysis confirms a clear and specific relationship between HR and beta blockers in the treatment of HF.

- The use of beta-blockers did not significantly benefit people with HFrEF whose HR was 77 beats/min before the use of beta-blockers.

beats/min have the lowest total mortality rates and cardiovascular mortality rates (7). An observational study of 145,211 patients with HF reported a J-shaped relationship between hospital mortality and heart rate. They found that the mortality rate was the lowest among those with a heart rate of $70-75$ beats $/ \mathrm{min}$ (8). Both the American College of Cardiology/American Heart Association $(3,9)$ and European Society of Cardiology (5) guidelines recommend that patients with a heart rate higher than 70 beats/min after beta-blocker use should consider using ivabradine. This suggests that the heart rate should be controlled at about 70 beats/min with beta blockers. However, so far, no randomized controlled trials of beta blockers for $\mathrm{HF}$ were used as evidence for heart rate targets of 60 or 70 beats/min.

This systematic review of randomized controlled trials of betablockers in patients with HFrEF was conducted to assess the target heart rate of patients with HF treated with beta blockers.

\section{Methods}

We searched PubMed, Ovid, EMBASE, and Cochrane from 1966 to June 2021. No language restrictions were applied, and only human studies, clinical trials, randomized and controlled trials' publications were considered. "Heart failure" and "betablocker" were used as keywords. In addition, we searched recent meta-analyses or reviews of beta-blocker in heart failure and $\mathrm{HF}$ guidelines.

\section{Selection and data abstraction}

Two authors independently reviewed the results and selected studies that reported the effect of beta-blockers on all-cause mortality in patients with HFrEF. Studies were excluded if they did not report death at the end of the follow-up, used betablockers for one month or less, or enrolled less than 50 patients. Trials were excluded if there was no difference in the heart rate between the two groups at the end of the trial.

Two authors independently extracted all outcome data with subsequent discussion of any discrepancies. The outcomes from each study were extracted in intention-to-treat categories rather than per-protocol categories (that is, all outcomes were analyzed by randomization group to avoid bias from excluding patients who dropped out, were withdrawn, or did not adhere to treatment).

\section{Statistical analysis}

A meta-analyses and subgroup analysis were conducted using Review Manager, version 5.0 (The Cochrane Collaboration, Copenhagen, Denmark). We did cumulative analyses using Stata version 12.0. Owing to the relatively common outcome of interest, we calculated risk ratios (RRs) and $95 \%$ confidence interval (CI). We assessed and quantified statistical heterogeneity for each outcome of interest using the Cochran 0 test and the $\mathrm{I}^{2}$ statistic, respectively. The $\mathrm{I}^{2}$ statistic quantifies the percentage of statistical heterogeneity due to between-study variability. By convention, values $\leq 25 \%, 25 \%$ to $50 \%$, and $\geq 50 \%$ are considered to have low, moderate, and high amounts of heterogeneity, respectively. If the heterogeneity was high, the statistical method chose the random effect model.

\section{Results}

\section{Study selection and evaluation}

Among the 8 citations that we identified in our search, 106 were potentially eligible for inclusion. Consequently, 84 were excluded after a detailed review (Fig. 1).

\section{Studies included in the systematic review}

Table 1 shows the features from 22 (10-31) randomized trials. Three trials $(13,17,28)$ reported outcome data in subgroups (each of these subgroups is reported as a separate row in Table 1). Therefore, a total of 27 trials or subgroups were included in the statistical analysis. The randomization scheme was used in all the experiments, and loss of follow-up and withdrawal were

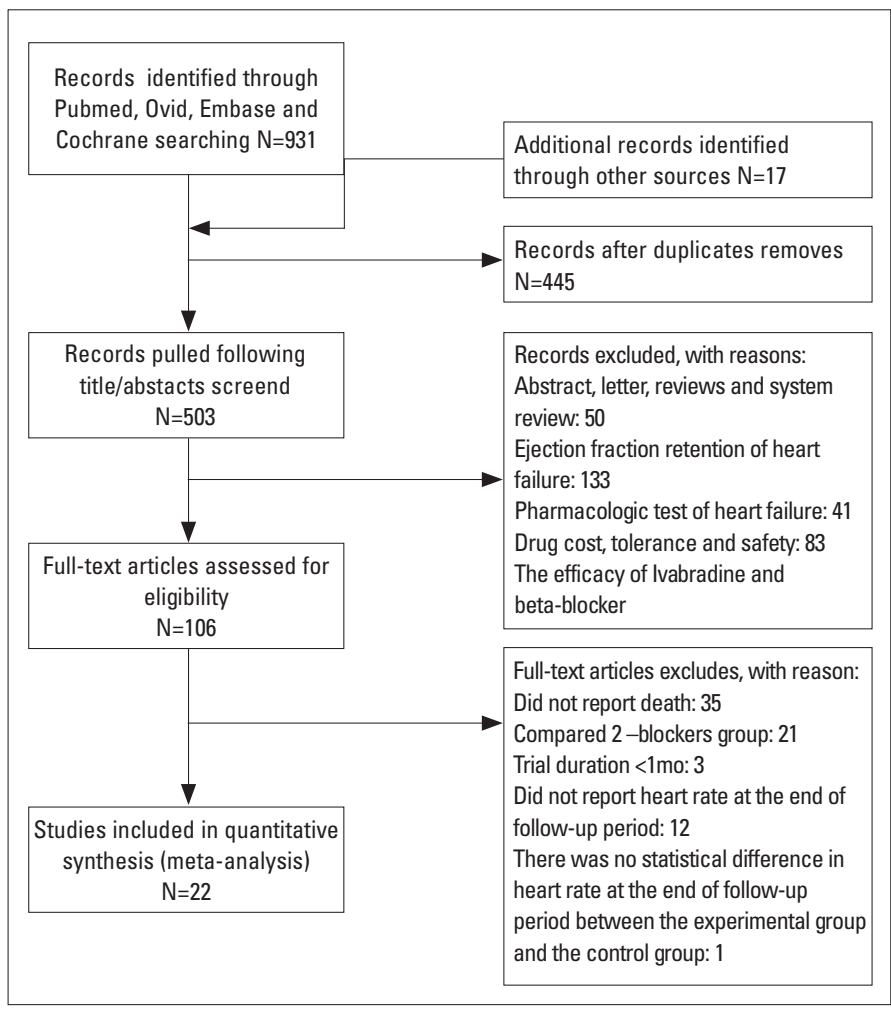

Figure 1. Study flow diagram 


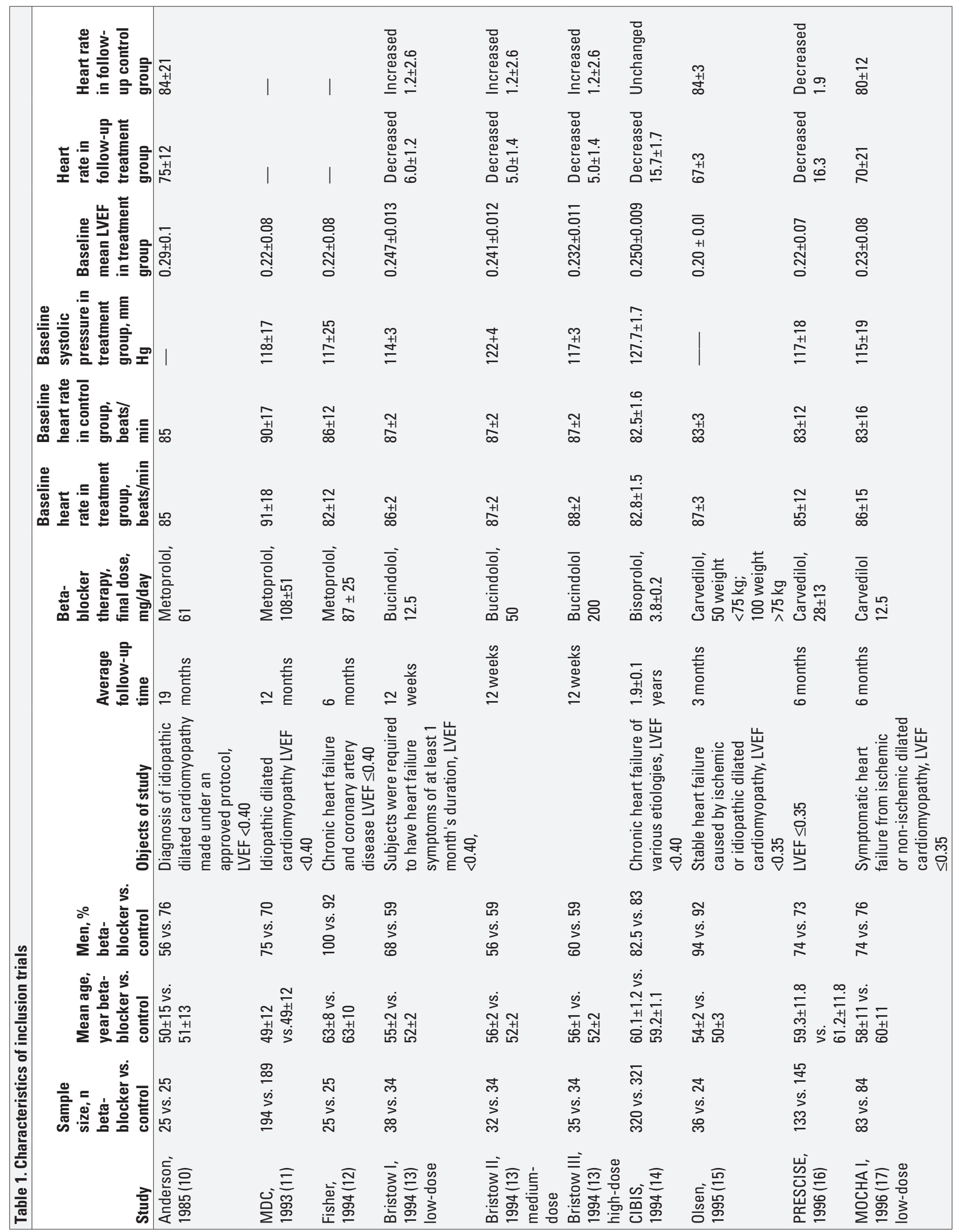




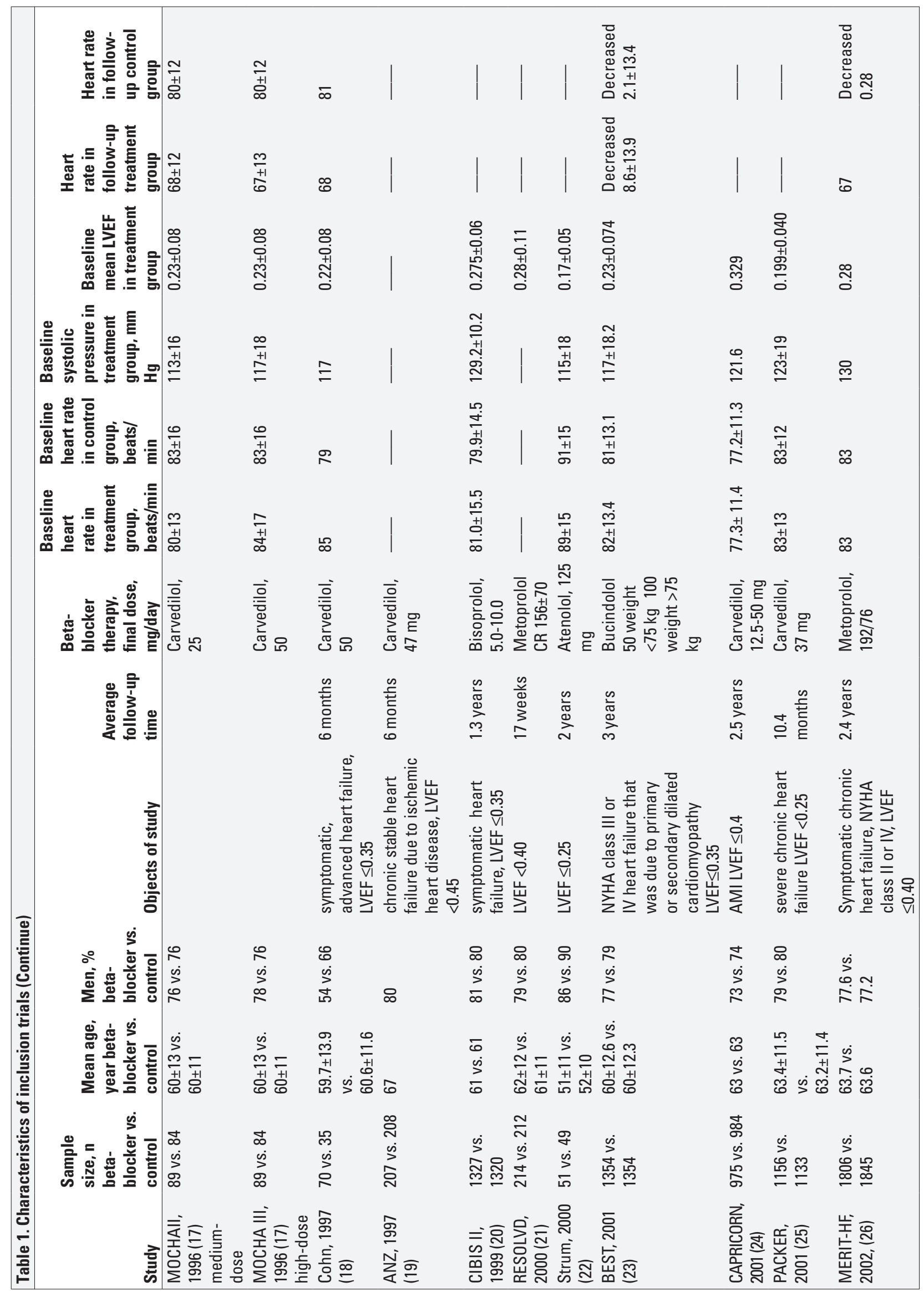




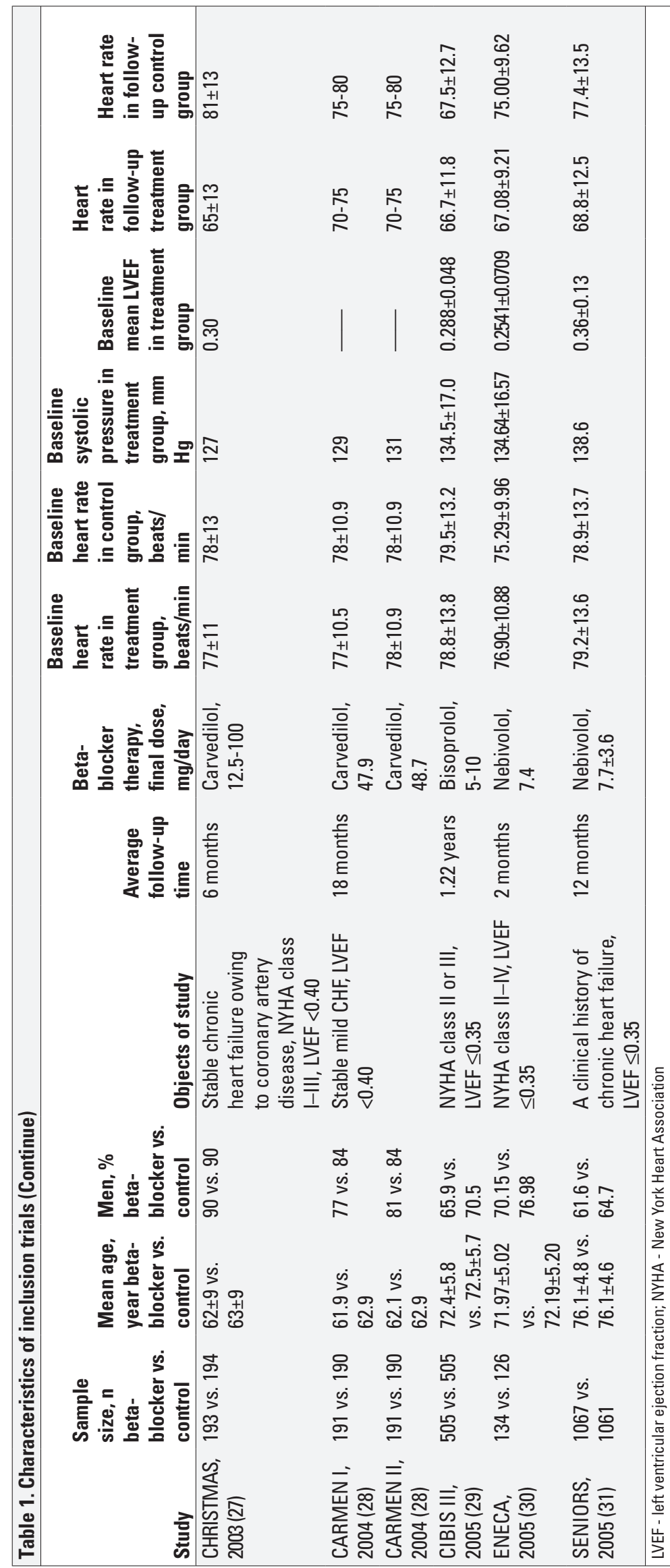

reported. The other experiments were carried out with a double blind design scheme, except Anderson1985, MDC1993, CIBIS1994, BEST2001, CAPRICORN2001, CARMEN2004. According to the Jadad scoring scale, all included trials were high-quality studies.

\section{Data synthesis}

Only 19 out of 27 trials or subgroups described endpoint heart rate. Except for the CARMEN trial, which controlled the heart rate within the range $70-75$ beats/min, the remaining reports described specific heart rate at the end of the trial (Fig. 2). The lowest end-point heart rate was reported in the CHRISTMAS trial, which controlled the heart rate at 65 beats/min. No clinical trial controlled the heart rate at 60 beats $/ \mathrm{min}$. Heart rate was controlled at 65-70 beats/min in 12 trials, $70-80$ beats/min in 5 trials, and above 80 beats/min in 3 trials. Only MERIT-HF and MOCHA III trials showed that beta-blockers reduced mortality in patients with HF in the 19 trials. The heart rate was controlled at 67 beats/min in both trials.

A total $25 / 27$ trials or subgroups provided baseline heart rate. The lowest baseline average heart rate was 76.90 beats/min in 25 clinical trials or subgroups, and the highest was 91 beats/min. Subgroup analysis was based on the baseline heart rate level (Fig. 3). RR and $95 \% \mathrm{Cl}$ were 0.77 $(0.71,0.83)$ and $0.86(0.76,0.97)$ in the subgroup with baseline heart rate $>80$ beats/min and subgroup with baseline $\leq 80$ beats/min, respectively. The use of beta-blockers in the treatment of HF in people with a baseline heart rate $>80$ beats/min and $\leq 80$ beats/min was beneficial. However, the benefits of beta-blockers decreased in people with heart rate lower than 80 beats/min. It is still unclear whether the benefits of beta-blocker therapy for HF are likely to disappear with a further reduction in baseline heart rate. The lowest baseline heart rate (approximately 77 beats/min) was reported in ENCA, CAPRICORN, CHRISTMAS, and CARMEN I. A meta-analysis of the four trials (Fig. 4) showed that $\mathrm{RR}$ and $95 \% \mathrm{Cl}$ were $0.82(0.67,1.00)$, indic ating no significant difference in the mortality rate between the beta-blockers and control groups. The sensitivity analysis using the random-effect model yielded significantly similar results.

Furthermore, subgroup analysis was performed according to the heart rate at the end of the trial (Fig. 5). The heterogeneity was low, and the fixed-effect model was used. $\mathrm{RR}$ and $95 \% \mathrm{Cl}$ were $0.92(0.82,1.02)$ and $0.77(0.65,0.92)$ in two subgroups with heart rate control $\geq 70$ beats/min and 60-70 beats/min, respectively. These data suggested no significant difference in mortality of patients with HF who used beta-blockers and controlled their heart rate above 70 beats/min compared with placebo therapy. Controlling heart rate at $60-70$ beats/min can significantly reduce mortality. We can infer that the benefit of beta-blockers in the treatment of HF mainly occurs through the reduction of heart rate. Beta-blockers are beneficial only when used to 


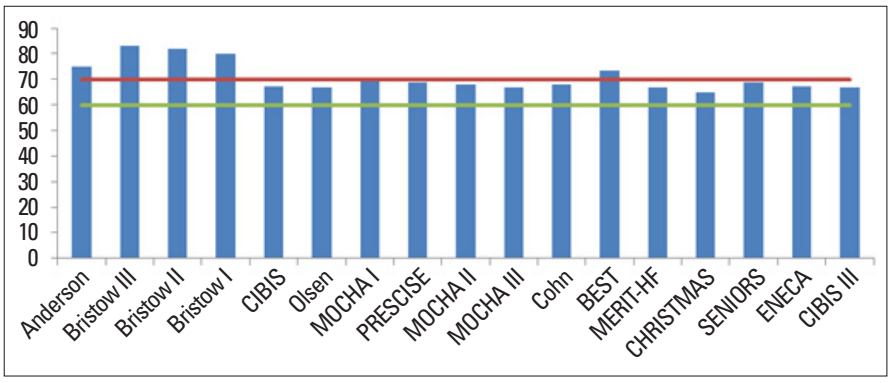

Figure 2. Endpoint heart rate of included trials

reduce heart rate below 70 beats/min. The sensitivity analysis using the random-effect model yielded significantly similar results.

The cumulative meta-analysis was performed according to the end-point heart rate from high to low (Fig. 6). Accumulated to MOCHA I trial, there was no significant difference in mortality between the experimental group and the control group (RR=0.91, $95 \% \mathrm{CI} 0.82-1.02$ ). Accumulated to SENIORS trial (heart rate controlled 68.8 beats/min), there was a difference in mortality between the experimental and the control groups ( $R R=0.90,95 \%$ $\mathrm{Cl} 0.82-0.99$ ). The end-point heart rate of MOCHA I trial was 70 beats/min and that of SENIORS trial was 68.8 beats $/ \mathrm{min}$. The results showed no significant differences in mortality between placebo and beta-blockers in controlling the heart rate to 70 beats/min. The mortality rate was reduced when the heart rate was lowered to 68.8 beats/min by beta-blockers compared with that of the control group. This outcome was consistent with the results of subgroup analysis.

In 27 trials or subgroups, only CIBIS II, MERIT-HF, and MOCHA III showed that the use of beta-blockers reduced the mortality in patients with HFrEF, whereas there was no significant difference in the mortality between the experimental and the control groups in other 24 trials or subgroups. The heterogeneity of the inclusion test was low, and the fixed effect model was adopted. Our meta-analysis (Fig. 7) showed that betablocker therapy reduced the mortality in patients with HFrEF (RR=0.79, 95\% Cl 0.74-0.84).

\section{Discussion}

Heart rate is an independent risk factor for HF (6). The resting heart rate has been identified as a particular modifying risk factor for $\mathrm{HFrEF}$ (32). Previous evidence $(33,34)$ suggests that the higher reduction in the heart rate resulted in a better overall prognosis in patients with HF. Therefore, recent guidelines $(3,5)$ recommend stricter heart rate control with a target of 60 or 70 beats/min. However, there is no sufficient basis for setting these heart rate targets. Observational studies (7) have shown that for the general population, the total mortality and cardiovascular mortality rates were the lowest in people with heart rate of approximately 65 beats/min. For patients with HFrEF, the mortality rate was the lowest when the heart rate was between 70 and 75 beats/min (8). All these results suggest that for patients with $\mathrm{HF}$, heart rate is clearly related to mortality. Not the lower the better, but there is a heart rate range to make mortality the lowest. Subgroup analysis according to baseline heart rate showed that there was no significant benefit from beta-blockers in the population with baseline heart rate of 77 beats/min. In addition, the cumulative meta-analysis showed statistical differences until the end-stage heart rate was below 70 beats/min. The RR values gradually decreased along with the decrease of heart rate, but the decrease range became smaller and smaller. Accumulated to CHRISTMAS trial, RR value was higher than before, which may be related to the sample size of the test itself. It may also be that when the heart rate is controlled to 65 beats/ $\mathrm{min}$, the heart rate further decreases without more benefit or even the benefit begins to decrease. This needs further trial confirmation.

Beta-blockers reduce morbidity and mortality in patients with HFrEF (1). Nonetheless, it remain unclear whether the key mechanisms underpinning their benefits are protection of adrenergic receptors from heightened sympathetic activity or reduction in heart rate. It is also uncertain whether the efficacy of beta-blocker is related to dose, reduction in heart rate, or the achieved heart rate $(35,36)$. Whether clinicians should strive to achieve a target heart rate or a target dose of beta-blocker remains unanswered.

A large retrospective clinical (37) study involving 1,669 patients suggested that the use of beta-blockers to achieve the target dose or target heart rate (50-70 beats per minute) had similar benefits and that controlling the heart rate after reaching the target dose was still beneficial. The new premise was that the aim of using beta blockers is not to achieve the maximum tolerable dose, but to control heart rate $(38,39)$.

The SHIFT (32) trial is the first trial to specifically test the effect of isolated heart-rate reduction on outcomes in a population with HF. Treatment with ivabradine was associated with an average reduction in heart rate of $15 \mathrm{bpm}$ from a baseline value of $80 \mathrm{bpm}$, which was largely maintained throughout the course of the study. In the SHIFT population, patients with heart rates higher than the median were at increased risk of an event and received greater event-reducing benefit from ivabradine than did those with heart rates lower than the median. This is consistent with our conclusion.

The relationship between dose and efficacy of beta-blockers was not evaluated in this paper. However, our subgroup analysis confirmed that the use of beta blockers did not reduce mortality in patients with baseline heart rate of 77 beats $/ \mathrm{min}$. In the SHIFT (32) trial, 3,181 (56\%) patients on beta blockers were treated with at least $50 \%$ of the target doses, and 1,488 $(26 \%)$ were at target doses. The results showed that the use of ivabradine on this basis benefited by lowering the heart rate, which suggests that the dose of the Beytagh blocker is not critical. Compared with placebo treatment, there was no significant difference in mortality among those using beta blockers that controlled heart rate over 70 beats $/ \mathrm{min}$. Controlling heart rate at $60-70$ beats/min can significantly reduce mortality. The cumulative meta-analysis also showed that there was no significant difference in the mortality between placebo and beta-blocker groups when control- 


\begin{tabular}{|c|c|c|c|c|c|c|c|c|c|c|}
\hline Study or Subcroup & \multicolumn{2}{|c|}{ Experimental } & \multicolumn{2}{|c|}{ Control } & \multicolumn{2}{|r|}{ Risk Ratio } & \multicolumn{4}{|c|}{$\begin{array}{c}\text { Risk Ratio } \\
\text { M-H. Fixed. } 95 \% \mathrm{Cl}\end{array}$} \\
\hline \multicolumn{7}{|c|}{15.2 .1 baseline HR $>80$ beatsmin } & & & & \\
\hline Anderson1985 & 5 & 25 & 6 & 25 & $0.4 \%$ & $0.83[0.29,2.38]$ & & & & \\
\hline BEST2001 & 411 & 1354 & 449 & 1354 & $27.2 \%$ & $0.92[0.82,1.02]$ & & $=$ & 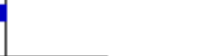 & \\
\hline Bristow/1994 & 1 & 3 & 2 & 34 & $0.1 \%$ & $0.45[0.04,4.72]$ & & & & \\
\hline Bristow01994 & 3 & 32 & 2 & 34 & $0.1 \%$ & $1.59[0.28,8.93]$ & & & & \\
\hline Bristowiln994 & 0 & 35 & 2 & 34 & $0.2 \%$ & $0.19[0.01,3.91]$ & & & & \\
\hline CIBIS1994 & 53 & 320 & 67 & 321 & $4.1 \%$ & $0.79[0.57,1.10]$ & & $\cdot$ & & \\
\hline CIBIS 01999 & 156 & 1327 & 228 & 1320 & $13.8 \%$ & $0.68[0.56,0.82]$ & & + & & \\
\hline Cohn1997 & 2 & 70 & 2 & 35 & $0.2 \%$ & $0.50[0.07,3.40]$ & & & & \\
\hline Fisher1994 & 1 & 25 & 2 & 25 & $0.1 \%$ & $0.50[0.05,5.17]$ & & & & \\
\hline MDC1993 & 23 & 194 & 21 & 189 & $1.3 \%$ & $1.07[0.61,1.86]$ & & - & & \\
\hline MERIT HF2002 & 97 & 1806 & 154 & 1845 & $9.2 \%$ & $0.64[0.50,0.82]$ & & $T$ & & \\
\hline МOCHA I1996 & 12 & 83 & 13 & 84 & $0.8 \%$ & $0.93[0.45,1.93]$ & & & & \\
\hline MOCHA口1996 & 6 & $\infty$ & 13 & 84 & $0.8 \%$ & $0.44[0.17,1.09]$ & & & & \\
\hline MOCHÄIII996 & 1 & $\infty 9$ & 13 & 84 & $0.8 \%$ & $0.07[0.01,0.54]$ & & & & \\
\hline Olsen1995 & 1 & 36 & 0 & 24 & $0.0 \%$ & $2.03[0.09,47.78]$ & & & & \\
\hline PACKER2001 & 130 & 1156 & 190 & 1133 & $11.6 \%$ & $0.67[0.54,0.83]$ & & + & & \\
\hline PRECISE1996 & 6 & 133 & 11 & 145 & $0.6 \%$ & $0.59[0.23,1.56]$ & & & & \\
\hline Sturm2000 & 8 & 214 & 17 & 212 & $1.0 \%$ & $0.47[0.21,1.06]$ & & & & \\
\hline Subtotal $(95 \%$ Cl) & & 7026 & & 6982 & $72.4 \%$ & $0.77[0.71,0.83]$ & & i & & \\
\hline Total events & 916 & & 1192 & & & & & & & \\
\hline \multicolumn{11}{|c|}{ Herogeneity: $\mathrm{Chi}^{2}=27.49, \mathrm{df}=17(\mathrm{P}=0.05) ; \mathrm{I}^{2}=38 \%$} \\
\hline \multicolumn{11}{|c|}{ Test for owerall effect: $Z=6.80(P<0.00001)$} \\
\hline \multicolumn{11}{|c|}{ 15.2.2 baseline HR $\leq 80$ beats/min } \\
\hline CAPRICORN2001 & 116 & 975 & 151 & 984 & $9.1 \%$ & $0.78[0.62,0.97]$ & & $\boldsymbol{\top}$ & & \\
\hline CARMEN I2004 & 14 & 191 & 14 & 190 & $0.9 \%$ & $0.99[0.49,2.03]$ & & $\longrightarrow$ & & \\
\hline CARMEN 02004 & 14 & 191 & 14 & 190 & $0.9 \%$ & $0.99[0.49,2.03]$ & & & & \\
\hline CHRISTMAS2003 & 7 & 190 & 5 & 194 & $0.3 \%$ & $1.41[0.45,4.36]$ & & & & \\
\hline CIBIS $\| 6005$ & 65 & 505 & 73 & 505 & $4.4 \%$ & $0.89[0.65,1.21]$ & & 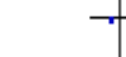 & & \\
\hline ENECA2005 & 7 & 134 & 7 & 126 & $0.4 \%$ & $0.94[0.34,2.61]$ & & & & \\
\hline SENIORS2005 & 169 & 1067 & 192 & 1061 & $11.7 \%$ & $0.88[0.72,1.06]$ & & 7 & & \\
\hline Subtotal $(95 \% \mathrm{Cl})$ & & 3256 & & 3250 & $27.6 \%$ & $0.86[0.76,0.97]$ & & $\varphi$ & 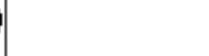 & \\
\hline Total events & 392 & & 456 & & & & & & & \\
\hline \multicolumn{11}{|c|}{ Herogeneity. $\mathrm{Chi}^{2}=1.97$, of $=\left.6(P=0.92)_{1}\right|^{2}=0 \%$} \\
\hline \multicolumn{11}{|c|}{ Test for owerall effect: $Z=2.38(P=0.02)$} \\
\hline Total $(95 \% \mathrm{Cl})$ & & 10282 & & 10232 & $100.0 \%$ & $0.79[0.74,0.85]$ & & 1 & & \\
\hline Total events & 1308 & & 1648 & & & & & & & \\
\hline \multicolumn{7}{|c|}{ Heterogeneity: $\mathrm{Chi}^{2}=30.55, \mathrm{df}=24(\mathrm{P}=0.17) ; \mathrm{I}^{2}=21 \%$} & $0.01 \quad 0.1$ & & & \\
\hline \multicolumn{7}{|c|}{ Test for owerall effect: $Z=6.99(P<0.00001)$} & $\begin{array}{l}0.01 \\
\text { Favours [expe }\end{array}$ & arimentall] & Favours [control] & 100 \\
\hline
\end{tabular}

Figure 3. Assessment of the effect of beta-blockers on mortality by subgroup analysis grouped according to baseline heart rate in the experimental group 


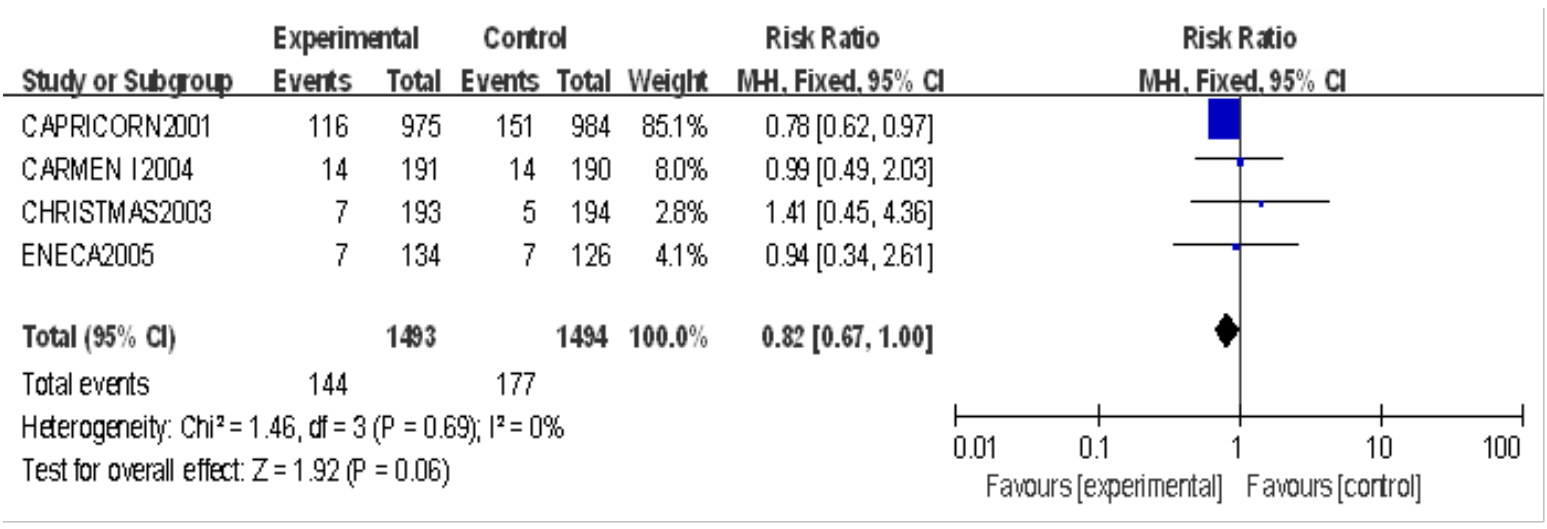

Figure 4. Effect of beta-blockers on mortality in population with a baseline heart rate of 77 beats/min

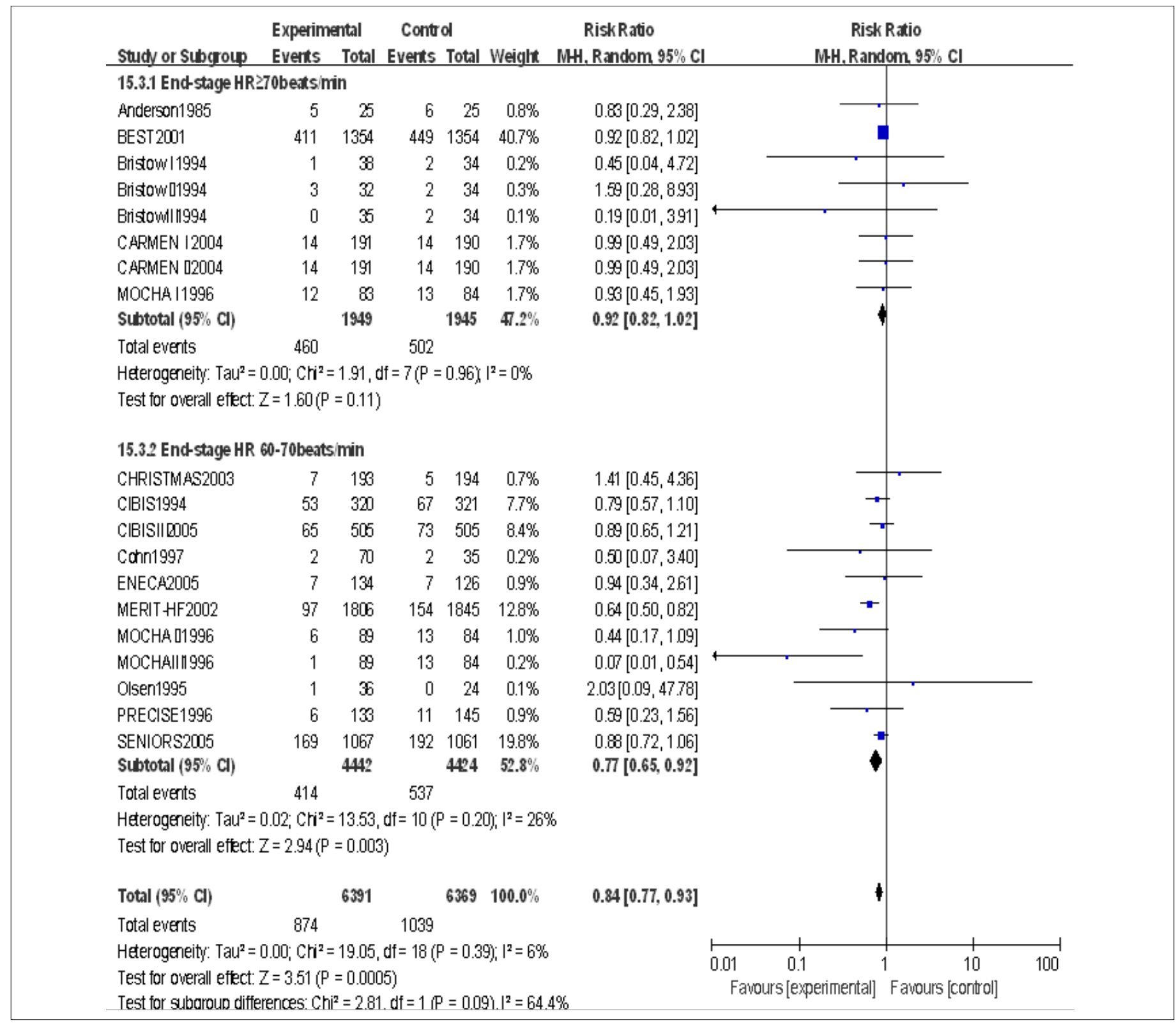

Figure 5. Assessment of the effect of beta-blockers on mortality by subgroup analysis grouped according to end-stage heart rate in the experimental group 


\section{Study}

ID

$\mathrm{RR}(95 \% \mathrm{Cl})$

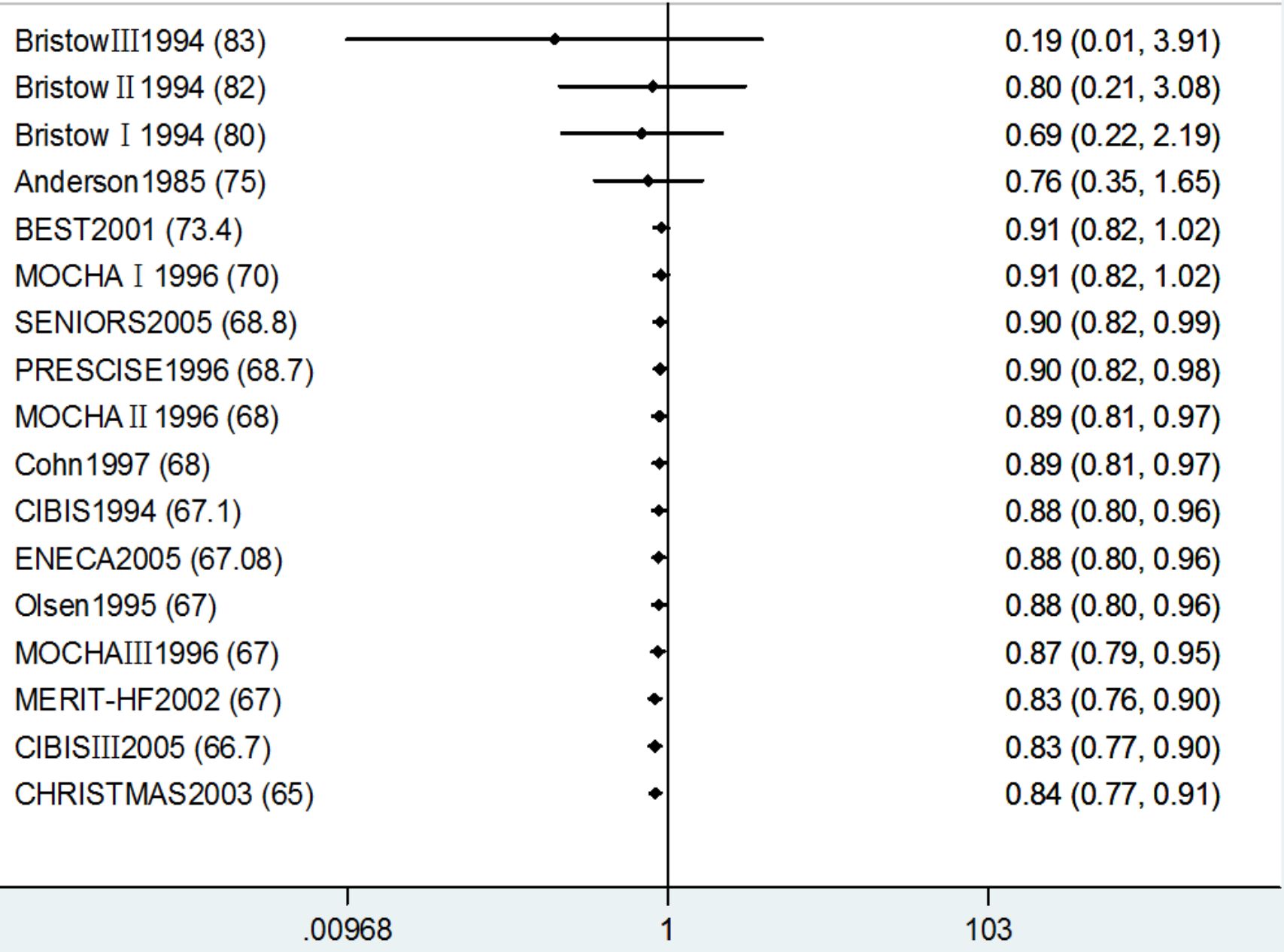

Figure 6. Cumulative meta-analysis based on end-point heart rate

ling the heart rate above 70 beats/min. The use of beta-blockers lowered the heart rate to 68.8 beats $/ \mathrm{min}$ and reduced the mortality compared with that in the control groups. Our findings suggest that beta-blockers can reduce mortality in the treatment of $\mathrm{HF}$ depending on the specific heart rate.

\section{Study limitations}

This was a meta-analysis. Background therapy of the included trials would have changed since these trials were conducted. In addition, the heart rate was not measured in a standardized fashion. Moreover, different patient study groups and different beta-blockers were used in different trials, which is a major reason for heterogeneity. The degree of heterogeneity is also assessed. A certain degree of heterogeneity does not affect the stability of the results.
Our analysis plan specified that only mortality should be analyzed as an outcome. The benefits of beta-blockers may manifest as improved symptoms, shortened hospitalization times and duration, reduced heart-related events, and so forth. These benefits are not analyzable in this paper.

\section{Conclusion}

The main benefit of beta-blockers in the treatment of $\mathrm{HF}$ is achieved by lowering heart rate. Patients with HFrEF whose heart rate is approximately 70 beats/min have the lowest mortality rate. In addition, the use of beta-blockers did not significantly benefit patients with HFrEF whose heart rate was 77 beats/min before the use of beta-blockers. In patients with HFrEF with a 


\begin{tabular}{|c|c|c|c|c|c|c|c|c|c|c|}
\hline Study or Subgroup & \multicolumn{2}{|c|}{ Experimental } & \multicolumn{2}{|c|}{ Control } & Weiclt & $\begin{array}{c}\text { Risk Ratio } \\
\text { MrH. Fixed, } 95 \% \mathrm{Cl}\end{array}$ & \multicolumn{4}{|c|}{$\begin{array}{c}\text { Risk Ratio } \\
\text { MrH. Fixed. } 95 \% \mathrm{Cl}\end{array}$} \\
\hline Anderson1985 & 5 & 25 & 6 & 25 & $0.4 \%$ & $0.83[0.29,2.38]$ & & & & \\
\hline ANZ1997 & 20 & 207 & 26 & 208 & $1.5 \%$ & $0.77[0.45,1.34]$ & & & & \\
\hline BEST2001 & 411 & 1354 & 449 & 1354 & $26.6 \%$ & $0.92[0.82,1.02]$ & & $=$ & 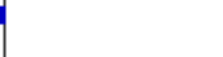 & \\
\hline Bristow/1994 & 1 & 3 & 2 & 34 & $0.1 \%$ & $0.45[0.04,4.72]$ & & & & \\
\hline Bristow01994 & 3 & 32 & 2 & 34 & $0.1 \%$ & $1.59[0.28,8.93]$ & & & & \\
\hline Bristowill11994 & 0 & 35 & 2 & 34 & $0.2 \%$ & $0.19[0.01,3.91]$ & $\leftarrow$ & & & \\
\hline CAPRICORN2001 & 116 & 975 & 151 & 984 & $8.9 \%$ & $0.78[0.62,0.97]$ & & $\rightarrow$ & & \\
\hline CARMEN I2004 & 14 & 191 & 14 & 190 & $0.8 \%$ & $0.99[0.49,2.03]$ & & . & & \\
\hline CARMEN 02004 & 14 & 191 & 14 & 190 & $0.8 \%$ & $0.99[0.49,2.03]$ & & $\longrightarrow$ & & \\
\hline CHRISTMAS2003 & 7 & 190 & 5 & 194 & $0.3 \%$ & $1.41[0.45,4.36]$ & & + & & \\
\hline CIBIS1994 & 53 & 320 & 67 & 321 & $4.0 \%$ & $0.79[0.57,1.10]$ & & $T$ & & \\
\hline CIBIS 01999 & 156 & 1327 & 228 & 1320 & $13.6 \%$ & $0.68[0.56,0.82]$ & & $T$ & & \\
\hline CIBIS॥ & 65 & 505 & 73 & 505 & $4.3 \%$ & $0.89[0.65,1.21]$ & & $\rightarrow$ & & \\
\hline Cohn1997 & 2 & 70 & 2 & 35 & $0.2 \%$ & $0.50[0.07,3.40]$ & & & & \\
\hline ENECA2005 & 7 & 134 & 7 & 126 & $0.4 \%$ & $0.94[0.34,2.61]$ & & & & \\
\hline Fisher1994 & 1 & 25 & 2 & 25 & $0.1 \%$ & $0.50[0.05,5.17]$ & & & & \\
\hline MDC1993 & 23 & 194 & 21 & 189 & $1.3 \%$ & $1.07[0.61,1.86]$ & & $\longrightarrow$ & & \\
\hline MERIT-HF2002 & 97 & 1806 & 154 & 1845 & $9.0 \%$ & $0.64[0.50,0.82]$ & & $\rightarrow$ & & \\
\hline MOCHAI1996 & 12 & 83 & 13 & 84 & $0.8 \%$ & $0.93[0.45,1.93]$ & & & & \\
\hline MOCHA 01996 & 6 & 9 & 13 & 84 & $0.8 \%$ & $0.44[0.17,1.09]$ & & & & \\
\hline MOCHAIIII996 & 1 & $\infty$ & 13 & 84 & $0.8 \%$ & $0.07[0.01,0.54]$ & & & & \\
\hline Olsen1995 & 1 & 36 & 0 & 24 & $0.0 \%$ & $2.03[0.09,47.78]$ & & & & \\
\hline PACKER 2001 & 130 & 1156 & 190 & 1133 & $11.4 \%$ & $0.67[0.54,0.83]$ & & $T$ & & \\
\hline PRECISE1996 & 6 & 133 & 11 & 145 & $0.6 \%$ & $0.59[0.23,1.56]$ & & & & \\
\hline RESOLVD2009 & 8 & 214 & 17 & 212 & $1.0 \%$ & $0.47[0.21,1.06]$ & & & & \\
\hline SENIORS2005 & 169 & 1067 & 192 & 1061 & $11.4 \%$ & $0.88[0.72,1.06]$ & & + & & \\
\hline Sturm2000 & 5 & 51 & 8 & 49 & $0.5 \%$ & $0.60[0.21,1.71]$ & & & & \\
\hline Total $(95 \% \mathrm{Cl})$ & & 10540 & & 10489 & $100.0 \%$ & $0.79[0.74,0.84]$ & & 1 & & \\
\hline Total events & 1333 & & 1682 & & & & & & & \\
\hline Heterogeneity: $\mathrm{Chi}^{2}=$ & $30.88, \mathrm{df}=$ & $26(P=$ & $0.23) ;\left.\right|^{2}=$ & $=16 \%$ & & & 01 & 1 & 10 & 100 \\
\hline Test for overall effect & $Z=7.10(P$ & $<0.000$ & & & & & Favours [expe & mental] & Favours [control] & \\
\hline
\end{tabular}

Figure 7. Forest flop for reducing mortality using beta-blockers

higher heart rate, the administration of beta-blockers to control heart rate to 70 beats/min can significantly reduce mortality. Further reduction of heart rate to 65 beats/min may not increase the benefit.

Acknowledgments: We would like to thank Hui Li, MD and Haibo $\mathrm{Xu}, \mathrm{MD}$, for their valuable input.

Conflict of interest: None declared.

Peer-review: Externally peer-reviewed.
Author contributions: Concept - J.Z., W.C.; Design - X.G., W.C.; Supervision - J.Z.; Fundings - None; Materials - Y.Z., H.H., J.Y.; Data collection \&/or processing - X.G., Y.Z., H.H.; Analysis \&/or interpretation - X.G., Y.Z., H.H.; Literature search - J.Y.; Writing - X.G.; Critical review - J.Z., W.C.

\section{References}

1. Brophy JM, Joseph L, Rouleau JL. Beta-blockers in congestive heart failure. A Bayesian meta-analysis. Ann Intern Med 2001; 134: 550-60. [Crossref] 
2. Lee HY, Baek SH. Optimal Use of Beta-Blockers for Congestive Heart Failure. Circ J 2016; 80: 565-71. [Crossref]

3. Yancy CW, Jessup M, Bozkurt B, Butler J, Casey DE Jr, Colvin MM, et al. 2017 ACC/AHA/HFSA Focused Update of the 2013 ACCF/AHA Guideline for the Management of Heart Failure: A Report of the American College of Cardiology/American Heart Association Task Force on Clinical Practice Guidelines and the Heart Failure Society of America. J Am Coll Cardiol 2017; 70: 776-803. [Crossref]

4. Yancy CW, Januzzi JL Jr, Allen LA, Butler J, Davis LL, Fonarow GC, et al. 2017 ACC Expert Consensus Decision Pathway for Optimization of Heart Failure Treatment: Answers to 10 Pivotal Issues About Heart Failure With Reduced Ejection Fraction: A Report of the American College of Cardiology Task Force on Expert Consensus Decision Pathways. J Am Coll Cardiol 2018; 71 : 201-30. [Crossref]

5. Ponikowski P, Voors AA, Anker SD, Bueno H, Cleland JG, Coats AJ, et al.; Authors/Task Force Members; Document Reviewers. 2016 ESC Guidelines for the diagnosis and treatment of acute and chronic heart failure: The Task Force for the diagnosis and treatment of acute and chronic heart failure of the European Society of Cardiology (ESC). Developed with the special contribution of the Heart Failure Association (HFA) of the ESC. Eur J Heart Fail 2016; 18: 891-975. [Crossref]

6. Vazir A, Claggett B, Jhund P, Castagno D, Skali H, Yusuf S, et al. Prognostic importance of temporal changes in resting heart rate in heart failure patients: an analysis of the CHARM program. Eur Heart J 2015; 36: 669-75. [Crossref]

7. Woodward M, Webster R, Murakami Y, Barzi F, Lam TH, Fang X, et al.; from the Asia Pacific Cohort Studies Collaboration. The association between resting heart rate, cardiovascular disease and mortality: evidence from 112,680 men and women in 12 cohorts. Eur J Prev Cardiol 2014; 21: 719-26. [Crossref]

8. Bui AL, Grau-Sepulveda MV, Hernandez AF, Peterson ED, Yancy CW, Bhatt DL, et al. Admission heart rate and in-hospital outcomes in patients hospitalized for heart failure in sinus rhythm and in atrial fibrillation. Am Heart J 2013; 165: 567-74. [Crossref]

9. Writing Committee Members, Yancy CW, Jessup M, Bozkurt B, Butler J, Casey DE Jr, et al.; American College of Cardiology Foundation/American Heart Association Task Force on Practice Guidelines. 2013 ACCF/AHA guideline for the management of heart failure: a report of the American College of Cardiology Foundation/ American Heart Association Task Force on practice guidelines. Circulation 2013; 128: e240-327.

10. Anderson JL, Lutz JR, Gilbert EM, Sorensen SG, Yanowitz FG, Menlove $\mathrm{RL}$, et al. A randomized trial of low-dose beta-blockade therapy for idiopathic dilated cardiomyopathy. Am J Cardiol 1985; 55: 471-5. [Crossref]

11. Waagstein F, Bristow MR, Swedberg K, Camerini F, Fowler MB, Silver MA, et al. Beneficial effects of metoprolol in idiopathic dilated cardiomyopathy. Metoprolol in Dilated Cardiomyopathy (MDC) Trial Study Group. Lancet 1993; 342: 1441-6. [Crossref]

12. Fisher ML, Gottlieb SS, Plotnick GD, Greenberg NL, Patten RD, Bennett SK, et al. Beneficial effects of metoprolol in heart failure associated with coronary artery disease: a randomized trial. J Am Coll Cardiol 1994; 23: 943-50. [Crossref]

13. Bristow MR, O'Connell JB, Gilbert EM, French WJ, Leatherman G, Kantrowitz NE, et al. Dose-response of chronic beta-blocker treatment in heart failure from either idiopathic dilated or ischemic cardiomyopathy. Bucindolol Investigators. Circulation 1994; 89: 1632-42. [Crossref]
14. A randomized trial of beta-blockade in heart failure. The Cardiac Insufficiency Bisoprolol Study (CIBIS). CIBIS Investigators and Committees. Circulation 1994; 90: 1765-73.

15. Olsen SL, Gilbert EM, Renlund DG, Taylor DO, Yanowitz FD, Bristow MR. Carvedilol improves left ventricular function and symptoms in chronic heart failure: a double-blind randomized study. J Am Coll Cardiol 1995; 25: 1225-31. [Crossref]

16. Packer M, Colucci WS, Sackner-Bernstein JD, Liang CS, Goldscher DA, Freeman I, et al. Double-blind, placebo-controlled study of the effects of carvedilol in patients with moderate to severe heart failure. The PRECISE Trial. Prospective Randomized Evaluation of Carvedilol on Symptoms and Exercise. Circulation 1996; 94: 2793-9. [Crossref]

17. Bristow MR, Gilbert EM, Abraham WT, Adams KF, Fowler MB, Hershberger RE, et al. Carvedilol produces dose-related improvements in left ventricular function and survival in subjects with chronic heart failure. MOCHA Investigators. Circulation 1996; 94: 2807-16. [Crossref]

18. Cohn JN, Fowler MB, Bristow MR, Colucci WS, Gilbert EM, Kinhal $\mathrm{V}$, et al. Safety and efficacy of carvedilol in severe heart failure. The U.S. Carvedilol Heart Failure Study Group. J Card Fail 1997; 3: 173-9. [Crossref]

19. Randomised, placebo-controlled trial of carvedilol in patients with congestive heart failure due to ischaemic heart disease. Australia/ New Zealand Heart Failure Research Collaborative Group. Lancet 1997; 349: 375-80.

20. The Cardiac Insufficiency Bisoprolol Study II (CIBIS-II): a randomised trial. Lancet 1999; 353: 9-13. [Crossref]

21. Effects of metoprolol CR in patients with ischemic and dilated cardiomyopathy: the randomized evaluation of strategies for left ventricular dysfunction pilot study. Circulation 2000; 101: 378-84. [Crossref]

22. Sturm B, Pacher R, Strametz-Juranek J, Berger R, Frey B, Stanek B. Effect of beta 1 blockade with atenolol on progression of heart failure in patients pretreated with high-dose enalapril. Eur J Heart Fail 2000; 2: 407-12. [Crossref]

23. Beta-Blocker Evaluation of Survival Trial Investigators, Eichhorn EJ, Domanski MJ, Krause-Steinrauf H, Bristow MR, Lavori PW. A trial of the beta-blocker bucindolol in patients with advanced chronic heart failure. N Engl J Med 2001; 344: 1659-67.

24. Dargie HJ. Effect of carvedilol on outcome after myocardial infarction in patients with left-ventricular dysfunction: the CAPRICORN randomised trial. Lancet 2001; 357: 1385-90. [Crossref]

25. Packer M, Coats AJ, Fowler MB, Katus HA, Krum H, Mohacsi P, et al.; Carvedilol Prospective Randomized Cumulative Survival Study Group. Effect of carvedilol on survival in severe chronic heart failure. N Engl J Med 2001; 344: 1651-8. [Crossref]

26. Wikstrand J, Hjalmarson A, Waagstein F, Fagerberg B, Goldstein S, Kjekshus J, et al.; MERIT-HF Study Group. Dose of metoprolol CR/ $\mathrm{XL}$ and clinical outcomes in patients with heart failure: analysis of the experience in metoprolol $\mathrm{CR} / \mathrm{XL}$ randomized intervention trial in chronic heart failure (MERIT-HF). J Am Coll Cardiol 2002; 40: 491-8. [Crossref]

27. Cleland JG, Pennell DJ, Ray SG, Coats AJ, Macfarlane PW, Murray $\mathrm{GD}$, et al.; Carvedilol hibernating reversible ischaemia trial: marker of success investigators. Myocardial viability as a determinant of the ejection fraction response to carvedilol in patients with heart failure (CHRISTMAS trial): randomised controlled trial. Lancet 2003; 362: 14-21. [Crossref] 
28. Komajda $M$, Lutiger $B$, Madeira $H$, Thygesen $K$, Bobbio $M$,

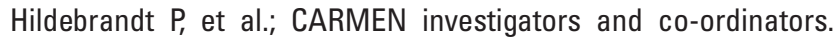
Tolerability of carvedilol and ACE-Inhibition in mild heart failure. Results of CARMEN (Carvedilol ACE-Inhibitor Remodelling Mild CHF EvaluatioN). Eur J Heart Fail 2004; 6: 467-75. [Crossref]

29. Willenheimer R, van Veldhuisen DJ, Silke B, Erdmann E, Follath F, Krum H, et al.; CIBIS III Investigators. Effect on survival and hospitalization of initiating treatment for chronic heart failure with bisoprolol followed by enalapril, as compared with the opposite sequence: results of the randomized Cardiac Insufficiency Bisoprolol Study (CIBIS) III. Circulation 2005; 112: 2426-35. [Crossref]

30. Edes I, Gasior Z, Wita K. Effects of nebivolol on left ventricular function in elderly patients with chronic heart failure: results of the ENECA study. Eur J Heart Fail 2005; 7: 631-9. [Crossref]

31. Flather MD, Shibata MC, Coats AJ, Van Veldhuisen DJ, Parkhomenko A, Borbola J, et al.; SENIORS Investigators. Randomized trial to determine the effect of nebivolol on mortality and cardiovascular hospital admission in elderly patients with heart failure (SENIORS). Eur Heart J 2005; 26: 215-25. [Crossref]

32. Swedberg K, Komajda M, Böhm M, Borer JS, Ford I, Dubost-Brama A, et al.; SHIFT Investigators. Ivabradine and outcomes in chronic heart failure (SHIFT): a randomised placebo-controlled study. Lancet 2010; 376: 875-85. [Crossref]

33. Huang RL, Listerman J, Goring J, Giesberg C, Nading MA, Butler J. Beta-blocker therapy for heart failure: should the therapeutic tar- get be dose or heart rate reduction? Congest Heart Fail 2006; 12: 206-10.

34. McAlister FA, Wiebe N, Ezekowitz JA, Leung AA, Armstrong PW. Metaanalysis: beta-blocker dose, heart rate reduction, and death in patients with heart failure. Ann Intern Med 2009; 150: 784-94. [Crossref]

35. Böhm M, Perez AC, Jhund PS, Reil JC, Komajda M, Zile MR, et al.; I-Preserve Committees and Investigators. Relationship between heart rate and mortality and morbidity in the irbesartan patients with heart failure and preserved systolic function trial (I-Preserve). Eur J Heart Fail 2014; 16: 778-87. [Crossref]

36. Kato N, Kinugawa K, Teruhiko I, Hironori M, Hisataka M, Toshiro I, et al. Differential impacts of achieved heart rate and achieved dose of $\beta$-blocker on clinical outcomes in heart failure with and without atrial fibrillation. Int J Cardiol 2014; 173: 331-3. [Crossref]

37. Corletto A, Fröhlich H, Täger T, Hochadel M, Zahn R, Kilkowski C, et al. Beta blockers and chronic heart failure patients: prognostic impact of a dose targeted beta blocker therapy vs. heart rate targeted strategy. Clin Res Cardiol 2018; 107: 1040-9. [Crossref]

38. Gelbrich G, Edelmann F, Inkrot S, Lainscak M, Apostolovic S, Neskovic AN, et al.; CIBIS-ELD investigators. Is target dose the treatment target? Uptitrating beta-blockers for heart failure in the elderly. Int J Cardiol 2012; 155: 160-6. [Crossref]

39. Flannery G, Gehrig-Mills R, Billah B, Krum H. Analysis of randomized controlled trials on the effect of magnitude of heart rate reduction on clinical outcomes in patients with systolic chronic heart failure receiving beta-blockers. Am J Cardiol 2008; 101: 865-9. [Crossref] 